\title{
Histological, Immunohistochemical and Molecular Alterations in Immature Mice Testes Due to Chronic Exposure to Mobile Phone Radiofrequency Radiation
}

\author{
Samir A. Nassar*, Ahmed Algazeery, Gamal A. Sayed Ahmed and Wafaa A. Abo El-Maaty \\ Zoology Dept., Faculty of Science, Zagazig University, Egypt \\ Corresponding author: Samir A. Nassar,email: sanassar@zu.edu.eg
}

\begin{abstract}
Background: increasing male infertility of obscured etiology may be attributed to environmental stressors. Extensive use of mobile phones has exposed the general population to unprecedented levels of radiofrequency radiations (RFRs) that may be implicated in the affected male reproductive health. Therefore, this study evaluated the possible toxicological effects of perinatal exposure of mice pups to $800-1800 \mathrm{MHz}$ like radiofrequency radiation (RFR) on the histological, immunohistochemical and molecular aspects of testicular tissue of mice.

Materials and Methods: ten pregnant females of Albino mice were selected and used in this research after the recognition of the first gestational day by the appearance of vaginal plug. They were categorized equally into 2 groups; G1: sham-exposed pregnant females, their pups served as the control group. G2: pregnant females exposed to mobile phone radiation for all the gestational period (prenatal exposure) and their pups were subjected to postnatal exposure for 45 consecutive days. Animals were continually exposed to RFR emitted by talk mode for 0.5 hour / day from a mobile test phone.

Results: mobile phone radiation affected the testicular structure and function via the degeneration of germ cells and Leydig cells. Moreover, it caused apoptosis of testicular cells as indicated by up regulation of caspase-3 and induced down regulation of PCNA at the immunohistochemical level confirmed by DNA damage at the molecular level. This onset may lead to infertility like condition due to RFR- exposure.

Conclusion: RFR at the studied frequency caused significant histological, immunohistochemical and molecular changes in the examined tissues. The results of this study and other similar studies, when extrapolated to man, they must alert the scientific community to the possibility that RFR may have long-term deleterious effects on the reproductive health.
\end{abstract}

Key words: mobile phone, testis, histology, caspase-3, PCNA, comet assay, mice.

\section{INTRODUCTION}

Decreasing fertility rates is a major cause for global concern, which may be addressed via evaluation of environmental factors. Nearly, 48.5 million couples worldwide were affected and $20-30 \%$ of these cases were due to male infertility of unknown etiology ${ }^{[1]}$.

Mobile phones operate between $800-2200 \mathrm{MHz}$ frequency bands which emit radiofrequency electromagnetic waves (RF-EMWs). Human bodies are dipoles acting as antennas that absorb radiation and convert it into alternating cross-current ${ }^{[2]}$.

Mobile phone usage is also associated with many health troubles like headache, neck pain, earache, tinnitus, fatigue, morning tiredness, painful fingers, eye symptoms and sleep disturbance ${ }^{[3]}$. Deleterious effects of RFR emitted by mobile phone on male reproductive organs are most frequently reported. Previous studies recorded RFR- induced sperm toxicity ${ }^{[4,5]}$, whereas few others have negated any effect on testes and sperms ${ }^{[6,7]}$. Microwaves emitted by cellular phones have resulted in histological changes in testes of male Wistar Albino rats [8,9]. Adult rabbits exposed to low intensity pulsed radiofrequency radiation emitted by a cell phone recorded a significant decrease in the diameter of seminiferous tubules ${ }^{[\mathbf{1 0}]}$. The use of mobile phones is more common in young aged males who mostly carry them in their pockets close to the scrotal area. This raised the public concerns about the

possible interaction of its EMWs with the male reproductive organs, especially testes ${ }^{[11,12]}$. Since germ cell damage can not only affect exposed populations, but also future generations, more studies must be performed to identify and confirm the negative effects of these nonionizing radiations, which can be useful in developing prevention and/or protective strategies. Therefore, the objective of this study was to assess the effect of perinatal exposure of mice pups to $860 \mathrm{MHz}$ of mobile phone RFR on histological, immunohistochemical and molecular aspects in their immature testes.

\section{MATERIAL AND METHODS}

\section{1-Animals}

Adult 8 males and 24 females of Albino mice were obtained from the animal house of the Faculty of Veterinary Medicine, Zagazig University. Animals involved in this study were maintained and used in accordance with the Animal Welfare Act and the Guide for the Care and Use of Laboratory Animals prepared by Zagazig University, Animal Ethical Committee. To reduce the effect of stress, animals were 
conditioned by placing them in plastic cages for 3 days before the experiment in the room in which they would be exposed to mobile phone microwaves. They were maintained on a 12:12 h light/dark cycle, at room temperature of $23^{\circ} \mathrm{C}$ and a relative humidity of $60 \%$. They were placed in groups of four $(1$ male +3 female $)$ for mating. Ten pregnant females of Albino mice were selected and used in this research after the recognition of the first gestational day by the appearance of vaginal plug. They were categorized equally into 2 groups; G1: sham-exposed pregnant females, their pups served as control. G2: pregnant females exposed to mobile phone radiation for all the gestational period (prenatal exposure) and their pups were subjected to postnatal exposure for 45 consecutive days.

\section{2-Mobile phone RFR in vivo exposure}

A radiofrequency GSM signal producer mobile phone (Nokia N8-00; frequency $860 \mathrm{MHz}$, SAR 1.09 $\mathrm{W} / \mathrm{kg}$ for head and $0.85 \mathrm{~W} / \mathrm{kg}$ for body) was used. Animals were continually exposed to RFR emitted by talk mode for 0.5 hour every day from a mobile test phones between 8:00 AM to 11:00 AM during both the pre and postnatal periods. The mobile phone was situated in close contact to exposure cage ${ }^{[13]}$. Controls were sham-exposed for the same period of time. During exposure, animals were provided with food and drinking water ad libitum.

\section{3- Animal sacrifice}

After the completion of the exposure period, pups of the control and experimental groups were euthanized, killed by decapitation and dissected for the removal of testes by non-traumatic technique. Each testis was cut into small pieces and fixed in $10 \%$ neutral formalin for at least $24 \mathrm{~h}$. , dehydrated in graded ethanol series, cleared in xylene then 3-5 $\mu \mathrm{m}$ sections were made.

4- For histopathological examination hematoxylin and eosin stain was used ${ }^{[14]}$.

\section{5-Immunohistochemical staining:}

Neutral buffered formalin (10\%) fixed testicular sections (5 $\mu$ thick) were dewaxed, hydrated to phosphate-buffered saline (PBS; $\mathrm{pH}$ 7.5). Immunostaining of caspase-3 and PCNA were carried out by using streptavidin/biotin immunoperoxidease method (LSAB kit, Dako Corp).

i. Caspase-3, a rabbit polyclonal antibody was used as a key marker for apoptosis.

ii. PCNA, a rabbit polyclonal antibody was used as a marker for proliferation activity of cells, according to the method of Greenwell et al. ${ }^{[15]}$.

For immunostaining pretreatment of slides by boiling for 10 minutes in $10 \mathrm{Mm}$ citrate buffer at $\mathrm{pH} 6$ for antigen retrieval and cooling sections at room temperature for 20 minutes. Then, incubate sections for overnight with the primary antibodies. Immunostaining was completed by the use of Ultravision detection system (cat number TP - 015- HD). Counterstaining was done using Mayer's hematoxylin.

\section{6- Molecular study}

The alkaline comet assay technic was carried out to study induction of DNA breaks in spermatogenic cells [16,17]. This method involves unwinding of DNA under alkaline conditions. Transfer crushed samples $(0.5 \mathrm{~g})$ to $1 \mathrm{ml}$ ice-cold PBS. Stir for $5 \mathrm{~min}$ and filter. We mixed $100 \mu \mathrm{l}$ of cell suspension with $600 \mu \mathrm{l}$ of low-melting agarose $(0.8 \%$ in PBS). We took $100 \mu \mathrm{l}$ of this mixture and spread on pre-coated slides. Slides were immersed in lyses buffer (0.045 M TBE, pH 8.4, containing $2.5 \%$ SDS) for 15 minutes then placed in electrophoresis chamber containing the same TBE buffer, but devoid of SDS. Conditions of electrophoresis were $2 \mathrm{~V} / \mathrm{cm}$ for 2 min and $100 \mathrm{~mA}$. Stain with ethidium bromide $(20 \mu \mathrm{g} / \mathrm{ml})$ at $4^{\circ} \mathrm{C}$. Observation was carried out on humid samples, the DNA fragment migration patterns of 100 cells for each treatment were evaluated with a fluorescence microscope using 40x objective (With excitation filter $420-490 \mathrm{~nm}$ [issue $510 \mathrm{~nm}$ ]). The comet tail lengths from the middle of the nucleus to the end of the tail were measured. A comet 5 image analysis software developed by Kinetic Imaging, Ltd. (Liverpool, UK) linked to a CCD camera was used to assess the quantitative and qualitative extent of DNA damage in cells by measuring the length of DNA migration and the percentage of migrated DNA. The percentage of fragmented DNA in the comet tail is a direct measure of DNA damage. Finally, the program calculates tail moment. The tail moment was defined as the percentage of DNA in the tail multiplied by the length between the center of the head and tail. Generally, 50 to 100 randomly selected cells were analyzed per sample.

\section{RESULTS \\ The histopathological results}

The light microscopy examination of testes of the control mice showed normal structure of seminiferous tubules (STs) which contained immature stages of spermatogenic cells and lumens mostly devoid of sperms (Fig. 1). In higher magnification for a part of the last field the seminiferous tubules exhibited clearly the immature stages of the spermatogenic cells; spermatogonia, spermatocytes, spermatids and interstitial tissue full of immature Leydig cells with a lumen empty of sperms (Fig. 2). However, exposure of the experimental animals to the non-ionizing radiation of mobile phone led to appearance of several histopathological lesions including disorganization and damaged germ cells inside the seminiferous tubules (Fig.3). Higher magnification of testicular tissue of the 
irradiated mice revealed apoptotic spermatogonia, damaged spermatocytes and spermatids, intra-tubular

vacuolization and degenerated interstitial tissue (Fig.4).
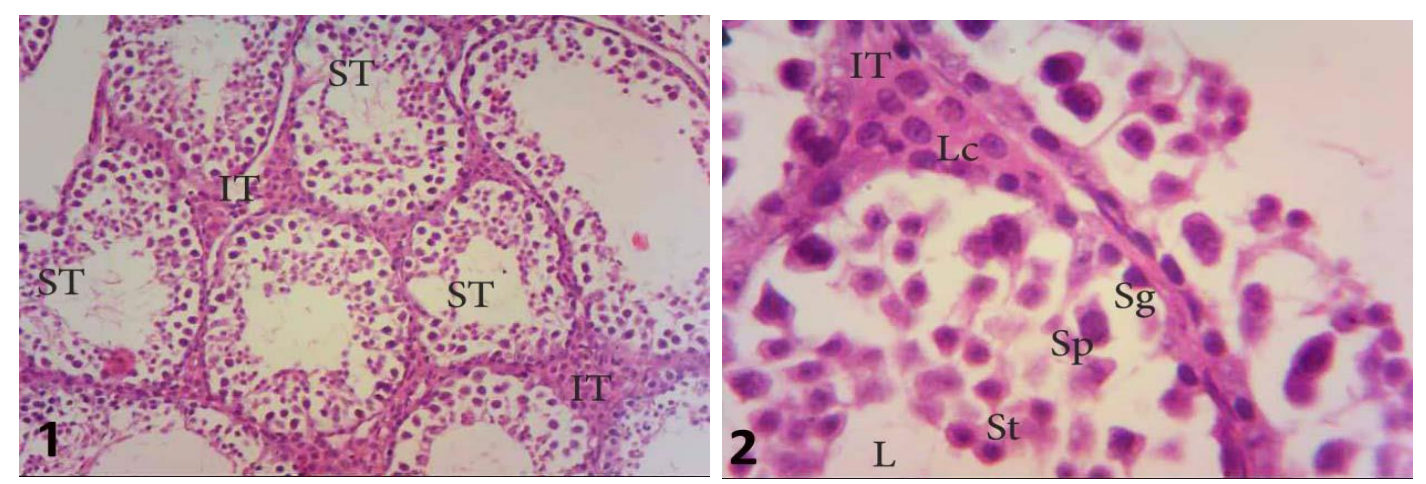

Fig.1: section of testis of control mice (1.5 month, H\&E, X400) showing seminiferous tubules (ST) containing immature stages of spermatogenic cells and lumens mostly devoid of sperms, interstitial tissue (IT) full of immature Leydig cells. Fig.2: section of testis of 1.5 month of control mice (H\&E, X1000) showing the different premature stages of spermatogenic cells; Sg: spermatogonia, Sp: spermatocytes, St: spermatids and the Leydig cells (LC) of interstitial tissue (IT) and L: lumen.
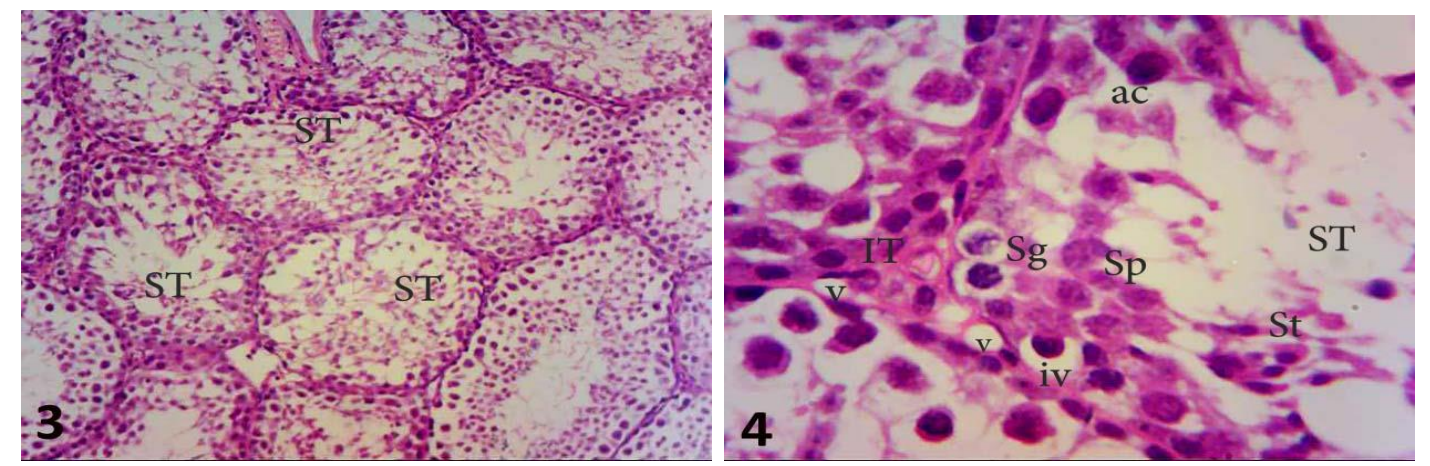

Fig.3: section of testis of RFR-exposed mice (1.5 month, H\&E, X400) demonstrating seminiferous tubules with disorganized and damaged spermatogenic cells. Fig.4: section of testis of microwave exposed mice (1.5 month, H\&E, $\mathrm{X} 1000)$ showing apoptotic spermatogonia (Sg), damaged spermatocytes (Sp) and spermatids (St), other apoptotic cells (ac) and intra-tubular vacuolization (iv), damaged and vacuolated interstitial tissue (IT).

\section{The immunohistochemical results}

\section{A. Caspase-3}

Application of caspase-3 immunostaining to testicular tissue of the control and irradiated animals resulted in mild brown reaction in the cytoplasmic areas of cells of the spermatogenic series of the control animals (Fig.5). Subjecting the immunohistochemical slides to the image analysis gave an average mean of optical density equal to 0.03017 (Table 1, Histogram 1). However, application of caspase-3 immunostaining to the testicular tissue of the irradiated animals resulted in strong immunoreactivity ( Fig.6) compared to the control group with an average mean of optical density equaling to 0.97350 and a highly significant increase $(\mathrm{P} \leq 0.0001)$ of $\mathrm{P}$ value (Table 1 , Histogram 1$)$.
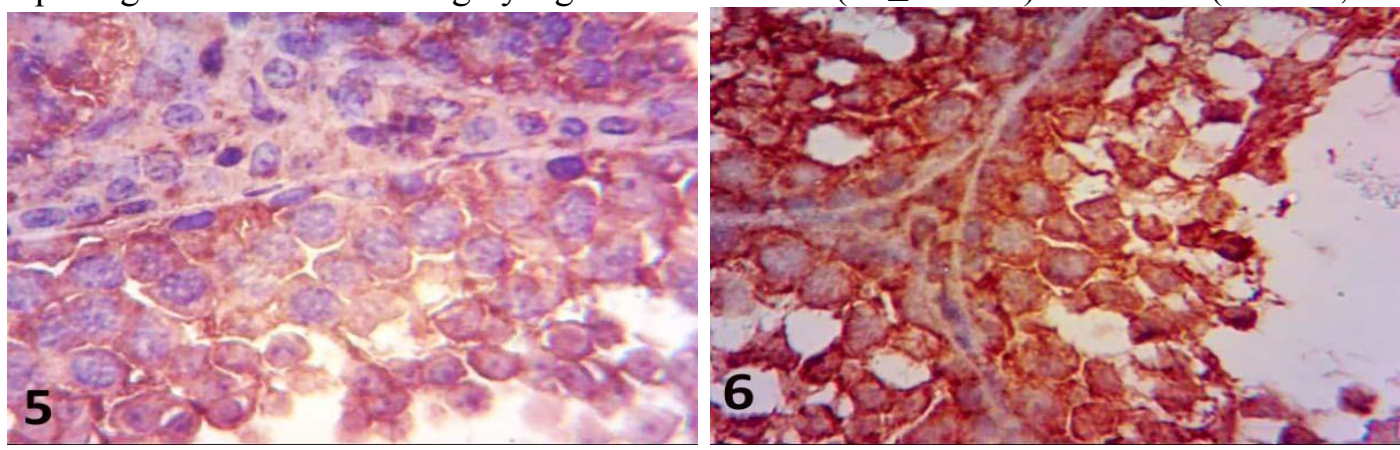
Fig.5: section of testis of a control mice (1.5 month, caspase-3 immunostaining, X1000) showing mild deposition of caspase-3 in cytoplasmic areas of testicular cells. Fig.6: section of testis of RFR- exposed mice (1.5 month, X1000) revealing a strong caspase- 3 reaction in the testicular tissue of exposed animals.

Table 1 : optical density of the average mean of caspas-3 in the control and irradiated groups histogram

\begin{tabular}{|l|l|l|}
\hline & Control & irradiated \\
\hline Average mean & 0.03017 & 0.97350 \\
\hline Stand. deviation & 0.00214 & 0.05160 \\
\hline P Value & \multicolumn{2}{|c|}{0.0001} \\
\hline
\end{tabular}

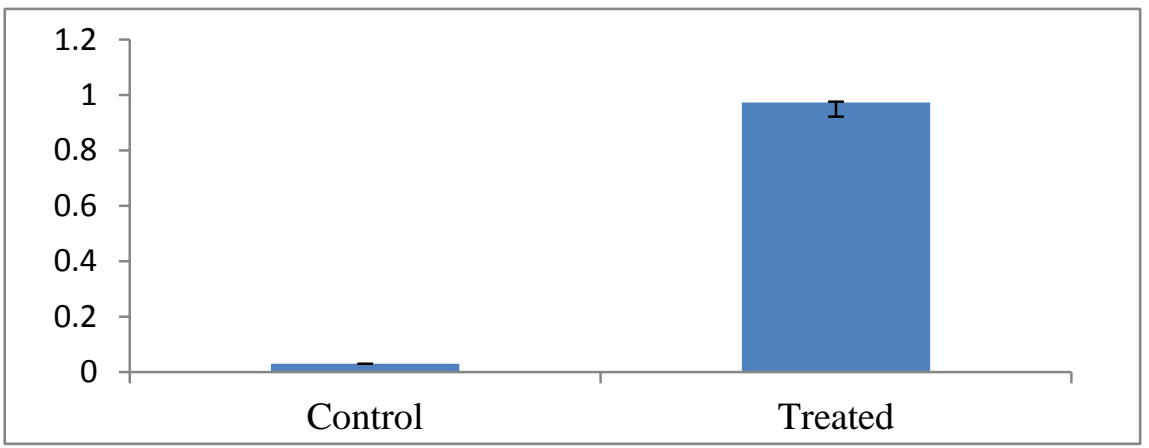

Histogram 1: a representative for the optical density of caspase -3

\section{B. PCNA}

Examination of testicular sections of the control group revealed a strong PCNA positive immunoreaction that appeared as brown nuclear deposits in spermatogonia and primary spermatocytes (Fig.7). On the other hand, testicular sections of irradiated animals showed little positive immunoreactivity in the damaged nuclei of the spermatogenic cells (Fig.8). The low positivity of PCNA in the testes of the irradiated animals recorded a significant decrease $(p \leq 0.002)$ compared to the control group (Table $2 \&$ histogram 2).
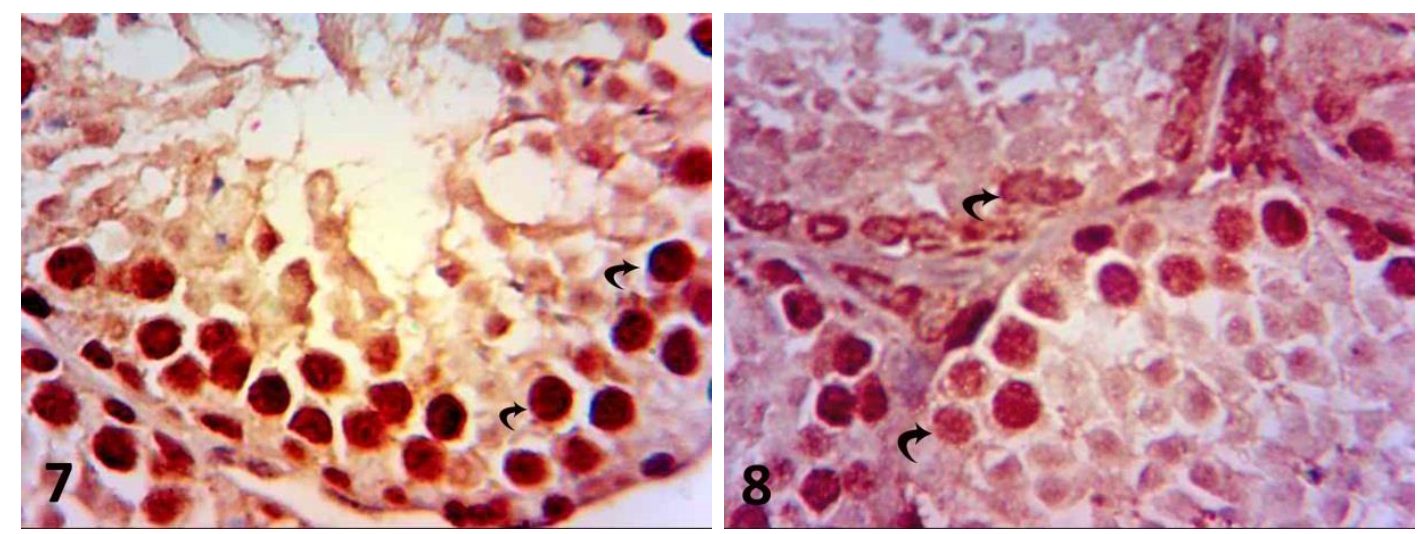

Fig. 7: section of testis of a control mice (1.5 month, PCNA immunostaining, X1000) showing strong reactivity of PCNA in nuclear areas of the spermatogonia and primary spermatocytes (curved arrows).

Fig.8: section of testis of RFR -exposed mice (1.5 month, X1000) revealing a low PCNA reactivity in the damaged nuclei of testicular cells of the exposed animals.

Table 2: optical density of the average mean of PCNA in the control and irradiated animals

\begin{tabular}{|l|l|l|}
\hline & Control & Irradiated \\
\hline Mean & 1391.0000 & 991.8333 \\
\hline Stand.dev. & 7.07017 & 6.01387 \\
\hline $\mathrm{T}$ ( Control) $\mathrm{p} \leq$ & 0.002 & \\
\hline
\end{tabular}




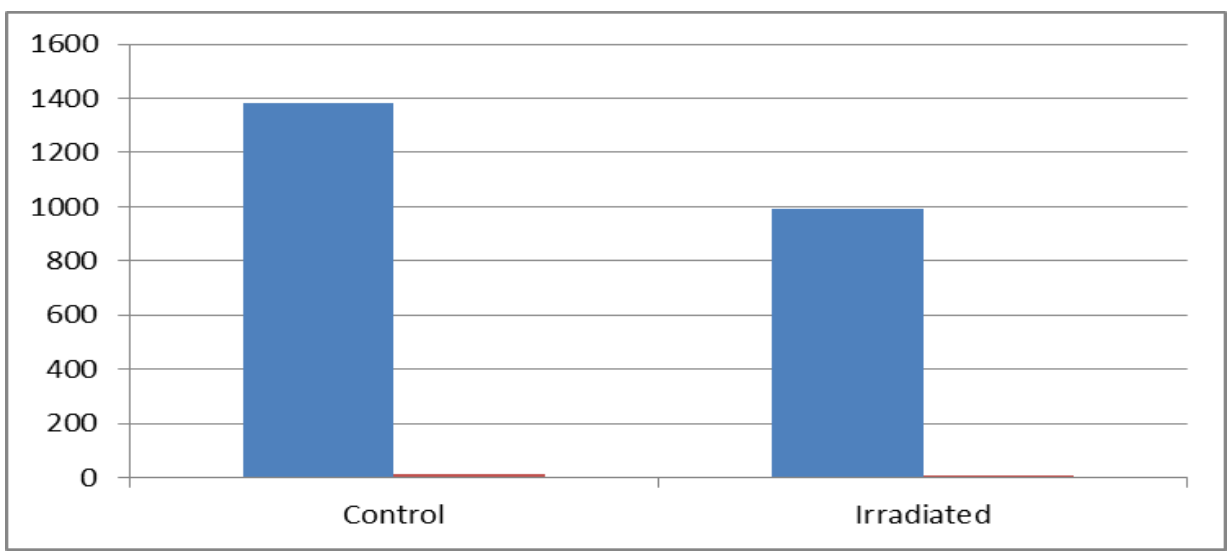

Histogram 2: a representative for the optical density of PCNA

\section{The molecular results}

The comet assay, or single cell gel electrophoresis (SCGE), is a commonly-used technic for detection, analyzing and measuring DNA damage in individual cells in response to different stressor stimuli. In the current study, changes in comet assay parameters revealed the extent of DNA damage by comet assay for each group. The testicular tissue of the control mice illustrated the normally-occurring DNA damage with a mean percentage of tail and tail moment of DNA measuring 2.39 and 5.043 respectively (Fig. 9, Table 3). Exposure to RFR led to approximately 1.3 and 1.7 -fold increase in the mean percentage of tail and tail moment of DNA measuring 3.05and 8.601 respectively recorded increased DNA damage in RFR-exposed group as compared to the control (Fig. 10\& table 3).
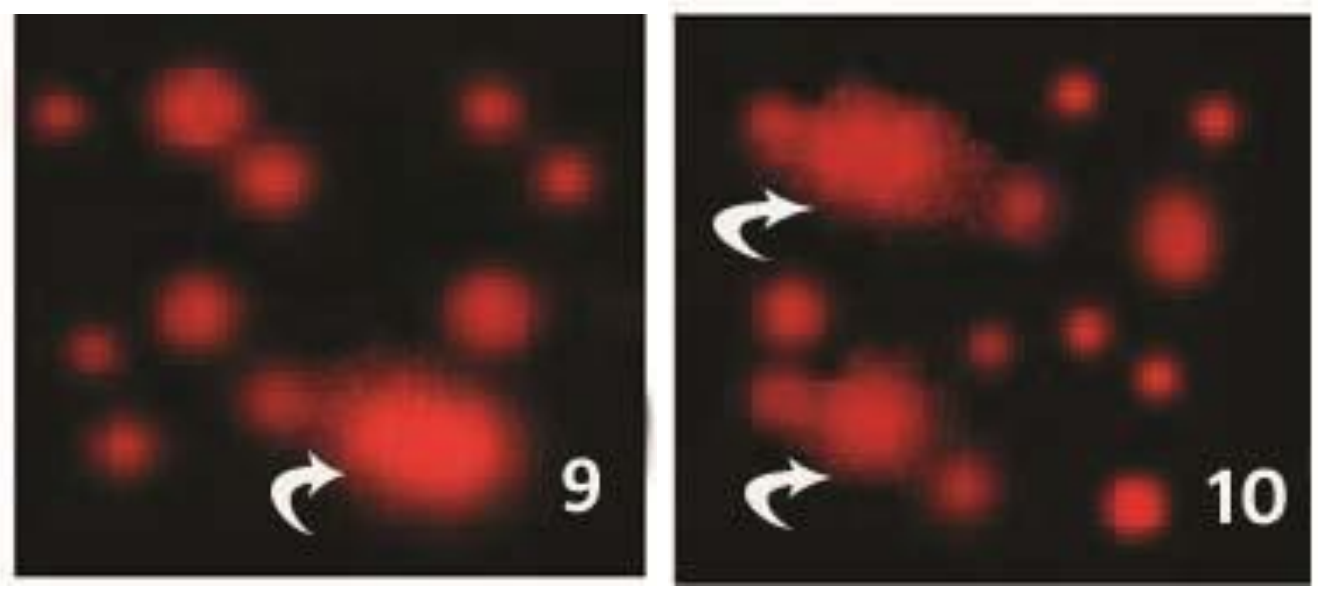

Fig.9 - Control testis

Fig.10 - Irradiated testis

Figs. 9, 10: gel pictures of comet assay analysis showing the extent of DNA damage in each comet group based on tail DNA\% and units of tail moment.

Table 3: values of comet parameters in the control and irradiated groups of mice

\begin{tabular}{|r|r|r|r|r|r|}
\hline TISSUE & $\%$ & $\%$ & $\boldsymbol{\mu m}$ & & Unit \\
\hline & Tailed & Untailed & Tail length & Tail DNA \% & Tail moment \\
\hline Testis (control) & 3 & 97 & 2.11 & 2.39 & 5.043 \\
\hline Testis (treated) & 8 & 92 & 2.82 & 3.05 & 8.601 \\
\hline
\end{tabular}




\section{DISCUSSION}

The evidence for the harmful effects of RFR on male fertility is still a matter of debate ${ }^{[18]}$. Several previous studies revealed that mobile phone usage led to decreased male fertility. However, other studies showed no confirmed correlation between male infertility and prolonged use of cell phone ${ }^{[2]}$. Therefore, the first target of the present investigation was to assess the consequences of increasing utility of cell phones on testes.

According to the results of this study, exposure of mice pups during the intrauterine and postnatal periods for half an hour/day resulted in different histopathological lesions in their testes including disorganization of germ cells, apoptotic spermatogonia, damaged spermatocytes and spermatids, intra-tubular vacuolar degeneration and degenerated Leydig cells. These detrimental effects markedly contribute to impaired testicular structure and consequently declined fertility and may be attributed to generation of free radicals due to the oxidative stress of radiation exposure. There was a conclusive evidence of free radical generation after exposure to microwave radiation field ${ }^{[19]}$.

These observations extend and support previous results of Nassar ${ }^{[13]}$ in 2009 which showed that exposure of the adult Albino mice to $900-1800 \mathrm{MHz}$ microwaves for 30 consecutive days ( 1 hour/day) affected the histological structure of mice testes at the cellular and subcellular level, particularly the Leydig cells and recorded an apoptosis-inducing effect on the spermatogenic cells. Another study recorded that exposure of male Wistar rats to mobile phone radiation $(6 \mathrm{~h} /$ day $\times 30$ days at $1.6 \mathrm{~W} / \mathrm{kg} \mathrm{SAR})$ led to affected both the testicular structure and function where they demonstrated detachment between the adjacent STs at several places and the number of Leydig cells was markedly-decreased via a non significant decrease in serum testosterone levels and testicular weight, whereas regular exercise through swimming ( $>3$ times a week and $>30$ min each session) led to a non significant increase in the testosterone concentrations and testicular weight ${ }^{[20]}$, but it might be significant if the time of the experiment was extended beyond 30 days.

This is nearly similar to the reports of Oyewopo et al. ${ }^{[21]}$ who stated that radiation of mobile phone caused a significant decrease in serum testosterone levels. Our findings are also consistent with some previous reports [22, 23] which concern the deleterious effects of EMF on testes at the frequency generated by cell phones; spermatozoa are particularly affected as demonstrated by stereological assessment of the number of cells. The number of Leydig cells, primary spermatocytes and spermatids were reduced due to EMF exposure compared to the control. The current observations also come in agreement with the previous reports of ELNaggar et al. ${ }^{[24]}$ who reported that exposure of male rats to $950 \mathrm{MHz}$ EMF for 3 hours / day, for 2 months induced degeneration, disorganization and atrophy in some STs with dilated interstitial spaces and highly reduced Leydig cells. Ruptured basement membranes of some STs with delaminated cells, decreased cellularity with highly reduced sperms in the lumen of STs. The oxidative stress induced by free radical generation may further contribute to gonadal dysfunction, hormonal imbalance, genetic defects and histological alterations [25].

Testing the immunohistochemical activity of caspase-3 and PCNA in the testicular tissue of mice in response to RFR exposure in the current study to evaluate the biochemical status underling the recorded histopathological alterations, the study recorded a significant increase in caspase- 3 immunoreactivity in the irradiated animals compared to the controls. The onset is being indicative to the increased state of cellular death and confirms and correlates the recorded histopathological apoptosis in the present study. This is in agreement with the study of Shabin et $\boldsymbol{a l} .{ }^{[26]}$ who recorded that the increased free radical load in the testes of $1800 \mathrm{MHz}$ mobile phone irradiated mice resulted in testicular apoptosis as evident by histological alterations, depletion of germ cells, up-regulation of pro-apoptotic proteins (Bax and p53), apoptotic proteins (cytochrome c), active executioner caspase-3, and down-regulation of anti-apoptotic proteins (Bcl-2 and Bcl-xL) and nuclear DNA repairing enzyme PARP-1. They also added that increased Bax expression coupled with reduced Bcl-2 and Bcl-xL expression may led to increased permeability of the mitochondrial outer membrane and consequently librated the cytochrome-c from mitochondria. This will subsequently induces the activation of caspase- 3 which cleaves the nuclear DNA repair enzyme PARP-1 and finally led to testicular apoptosis. Considering the progressive privilege of $2.45 \mathrm{GHz}$ wireless networks in our environment, exposure of Wistar rats to $2.45 \mathrm{GH}$ Wi-Fi radiation, induced a decrease in sperm parameters together with an increase in apoptosis-positive cells and caspase-3 activity in the seminiferous tubules in a timedependent exposure manner ${ }^{[27]}$.

The relationship between cellular apoptosis caused by RFR-exposure could be explained by the release of cytochrome $\mathrm{c}$ after mitochondrial damage resulting in DNA damage and apoptosis by activating the caspase mediated pathway ${ }^{[28]}$. Exposure to RFR had adverse effects on the proliferation and differentiation of spermatogonia, which may be helpful in understanding 
the pathogenesis of RFR-induced male infertility ${ }^{[29]}$. Therefore, we used PCNA as a biochemical tool to assess spermatogenesis. The mean number of PCNA positive testicular germ cells in the present investigation was significantly reduced in the irradiated group indicating disruption and loss in cell proliferation and spermatogenesis. This is in agreement with a previous study in which exposure of rats to $900 \mathrm{MHz}$ RF- EMWs fields for 1 hour/ day for 8 weeks resulted in significant decrease in PCNA immunoreactivity ${ }^{[30]}$. The comet assay is a sensitive and uncomplicated technic for the detection of the fragmented chromosomal DNA, an index of genome instability, as a late consequence of DNA damage at the level of individual eukaryotic cells. The alkaline comet assay is an accurate one for both single and double-strand breaks. Therefore, in the present investigation, we evaluated the DNA fragments level using alkaline comet assays in the spermatogenic cells and the study recorded from 1.3 to 1.7 -folds increase in DNA fragmentation in testes of the irradiated group relative to the controls. The observed high DNA damage in the RFR group clarifies induction of single stranded or alkali labile DNA lesions in germ cells and could be correlated with higher rates of lipid peroxidation in membranes of germ cells due to reactive oxygen species generated by RFR-exposure. The present results are in agreement with a previous study ${ }^{[31]}$ which indicated that exposure to $1800 \mathrm{MHz}$ RF-EMFs induced autophagy via the AMPK/mTOR signaling pathway and DNA damage in mouse spermatocyte cells at a SAR value of $4 \mathrm{~W} / \mathrm{kg}$ for $24 \mathrm{~h}$ and this process was mediated by ROS. Also, a previous study showed that the energy level associated with EMFs exposure was not sufficient to cause direct DNA damage, and it has been suggested that oxidative stress could be a key factor ${ }^{[32]}$. Based on results of present study it is concluded that, mobile phone radiation affected the testicular structure and function via the degeneration of germ cells and Leydig cells. Moreover, it caused apoptosis of testicular cells and induced down regulation of PCNA at the immunohistochemical level confirmed by DNA damage at the molecular level. This onset may lead to infertility like condition due to RFRexposure.

\section{REFERENCES}

1. Agarwal A, Mulgund A, Hamada A et al. (2015): A Unique View on Male Infertility around The Globe. Reproductive Biology and Endocrinology, 13: 37-45.

2. Agarwal A, Singh A, Hamada A and Kesari K (2011): Cell Phones Male Infertility: A Review of Recent Innovations in Technology Consequences. Int. Braz. J.Urol., 37: 432-454.

3. Stalin P, Abraham SB, Kanimozhy K, Prasad RV, Singh $Z$ and Purty AJ (2016): Mobile phone Usage and its health effects among adults in a semi-urban area of Southern India .J. Clin. Diagn. Res., 10: 14-16.

4.Agarwal A, Deepinder F, Sharma RK et al. (2008): Effect of cell phone usage on semen analysis in men attending infertility clinic: an observational study. Fertility Sterility, 89(1): 124-128.

5.Mailankot M, Kunnath AP, Jayalekshmi H, Koduru B and Valsalan R (2009): Radio frequency electromagnetic radiation (RFEMR) from GSM (0.9/1.8ghz) mobile phones induces oxidative stress and reduces sperm motility in rats. Clinics (Sao Paulo), 64:561-565.

6. Lee H, Pack-Je, kim T, Kim N, Choi S, Lee J, Kim S and Lee $Y$ (2010): The lack of histological changes of CDMA cellular phone-based radiofrequency on rat testis. Bioelectromagnetic, 31: 528-534.

7. Tumkaya L, Kalkan Y, Bas O et al. (2016): Mobile phone radiation during pubertal development has no effect on testicular histology in rats. Toxicology and Industrial Health, 32(2): 328-336.

8. Dasdag S, Ketani MA, Akdag Z, Ersay AR, Sari I, Demirtas OC and Celik MS (1999): Whole body microwave exposure emitted by cellular phones and testicular function of rats. Urol. Res., 27: 219-223.

9. Ozguner M, A Koyu, G Cesur, M Ural, F Ozguner, A Gokcimen and $N$ Delibas (2005): Biological and morphological effects on the reproductive organ of rats after exposure to electromagnetic field. Saudi Med. J., 26: 405-410.

10. Salama N, Tomoteru $K$ and Hiro-Omi $K$ (2010): Effects of exposure to a mobile phone on testicular function and structure in adult rabbit. Int. J. Androl., 33(1): 88-94.

11.Karaman MI, Gokce AM, Koca O, Karaman B, ozturk MI, Yurdakul $\mathbf{N}$ and Ercan F(2014): The effects of electromagnetic waves emitted by the cell phones on the testicular tissue. Arch. Ital. Urolrol., 30: 274-277.

12. Bin-Meferij MM and El-kott AF (2015): The radioprotective effects of Moringa oleifera against mobile phone electromagnetic radiation-induced infertility in rats. J. Clin. Exp. Med., 8(8): 12487-12497.

13. Nassar SA (2009): Do microwaves of mobile phone affect the testicular tissue structure? (A histopathological and ultrastructural study). The Egyptian Journal of Hospital Medicine, 3(7): 685-699.

14. Bancroft $J$ and Gamble $M$ (2008): Theory and Practice of Histological Techniques. Staining Methods. $7^{\text {th }}$ ed, Churchill Livingstone. London,7: 263-325.

15. Greenwell A, Foley JF and Maronpot RR (1991): An enhancement method for immunohistochemical staining of proliferating cell nuclear antigen in archival rodent tissues. Cancer Letters, 59: 251-256.

16.Singh NP, McCoy MT, Tice RR and Schneider EL (1988): A simple technique for quantitation of low levels of DNA damage in individual Cells. Exp. Cell Res., 175(1): 184-191.

17. Tice RR and Strauss GH (1995): The single cell gel electrophoresis Comet assay - a potential tool for detecting radiation-induced DNA damage in humans. Stem Cells, 13(1): 207-214. 
18.Olive PL, Banath JP and Durand RE (1990): Heterogeneity in radiation induced DNA damage and repair in tumor and normal cells using the "Comet" assay. Radiat .Res., 122: 86-94.

19. Sarookhani MR, Asiabanha Rezaei M, Safari A, Zaroushani $V$ and Ziaeiha $M$ (2010): The influence of $950 \mathrm{Mhz}$ magnetic field (Mobile phone radiation) on sex organ and adrenal functions of male rabbits. Afr. J. Biochem. Res., 5: 77-80.

20.D'Angelo C, Costantini E, Kamal MA and Reale $M$ (2015): Experimental model for ELF- EMF exposure: concern for human health. Saudi Journal of Biological Sciences, 22: 75-84.

21. Oyewopo AO, Olaniyi SK, Oyewopo CI and Jimoh AT (2017): Radiofrequency electromagnetic radiation from cell phone causes defective testicular function in male Wistar rats. Andrologia J., 49(10): 1-6.

22. Cetkin M, Kızılkan N, Demirel C, Bozdag Z, Erkılı S and Erbagci H (2017): Quantitative changes in testicular structure and function in rat exposed to mobile phone radiation. Andrologia J., 49:1-8.

23. Yahyazadeh A and Altunkaynak BZ (2019): Protective effects of luteolin on rat testis following exposure to 900 Mhz electromagnetic field. Biotechnic and Histochemistry, 94(4): 298-307.

24. EL-Naggar MI, EL-Sagheer AS and Ebaid AE (2019): The possible protective effect of vitamin $\mathrm{E}$ on adult Albino rat's testes exposed to electromagnetic field emitted from a conventional cellular phone. The Egyptian Journal of Hospital Medicine, 74 (4):873-884.

25.Kesari K, Kim K, Kumar S and Behari, J (2011): Effects of radiofrequency electromagnetic wave exposure from cellular phones on the reproductive pattern in male Wistar rats. Applied Biochemistry and Biotechnology, 164: 546-559.
26.Shahin S, Singh SP and Chaturvedi CM(2018): 1800 $\mathrm{MHz}$ Mobile Phone Irradiation Induced Oxidative and Nitrosative Stress Leads to P53 Dependent Bax Mediated Testicular Apoptosis In Mice, Mus Musculus. J. Cell Physiol., 233(9):1-15.

27. Shokri S, Soltani A, Kazemi M, Sardari D and Babapoor F (2015): Effects of Wi-Fi (2.45 Ghz) exposure on apoptosis, sperm parameters and testicular histomorphometry in rats: a time course study. Cell J., 17(2): 322-331.

28. Sun Y, Lin Y, Li H, Liu J, Sheng $X$ and Zhang W (2012): 2,5-Hexanedione induces human ovarian granulosa cell apoptosis through BCL-2, BAX, and Caspase-3 signaling Pathways. Arch. Toxicol., 86:205215.

29. Pandey N, Giri S, Das S and Upadhaya P (2017): Radiofrequency radiation (900 Mhz)-induced DNA damage and cell cycle arrest in testicular germ cells in Swiss Albino mice. Toxicology and Industrial Health, 33: 373-384.

30. Bin-Meferij $\mathbf{M M}$ and El-kott $\mathbf{A F ( 2 0 1 5 ) : ~ T h e ~}$ radioprotective effects of Moringa Oleifera against mobile phone electromagnetic radiation-induced Iinfertility in rats. Int. J. Clin. Exp. Med., 8: 12487-12497.

31. Li R et al. (2018): The protective effect of autophagy on DNA damage in mouse spermatocyte - derived cells exposed to $1800 \mathrm{MHz}$ radiofrequency electromagnetic fields. Cell. Physiol. Biochem., 48:29-41.

32. Friedman J, Kraus S, Hauptman Y, Schiff Yand Seger R (2007): Mechanism of short-term ERK activation by electromagnetic fields at mobile phone frequencies. Biochem. J.,405:559-568. 